\title{
Filiações partidárias e nomeações para cargos da burocracia federal (1999-2018)
}

\section{Felix Lopez 1}

Thiago Moreira da Silva 2

${ }^{1}$ Instituto de Pesquisa Econômica Aplicada / Diretoria de Estudos sobre o Estado, as Instituições e a Democracia, Rio de Janeiro / RJ - Brasil

2 Universidade do Estado do Rio de Janeiro / Instituto de Estudos Sociais e Políticos, Rio de Janeiro / RJ - Brasil

Quantos são e a quais partidos estão filiados os nomeados para os cargos do alto e médio escalão da burocracia federal brasileira? Há diferenças entre mandatos presidenciais? Para responder essas perguntas, construímos uma base de dados inédita referente aos filiados a partidos políticos em cargos de direção e assessoramento superior (DAS). Nossa análise descritiva aponta que a proporção de filiados aumentou nos governos do Partido dos Trabalhadores (PT) e é maior entre nomeados sem vínculo com o setor público. A concentração de poder entre os partidos - principalmente entre o partido presidencial e os demais - variou de modo significativo entre presidentes. O controle partidário sobre os nomeados filiados é mais brando nos cargos de nível intermediário e maior nos níveis superiores. Entretanto, os filiados são minoria, mesmo nos cargos de mais alto poder político-administrativo. Por isso, sugerimos que, possivelmente, as redes de conexão política que definem os quadros da burocracia decisória também se constroem por meios extrapartidários e compreendê-las se mostra decisivo para dimensionar o peso da política partidária na burocracia ministerial e reinterpretar como o Poder Executivo constrói e gerencia a coalizão de governo e seu apoio no Poder Legislativo.

Palavras-chave: cargos de confiança; nomeações políticas; burocracia; filiações partidárias; presidencialismo de coalizão.

\section{Afiliaciones partidarias y nombramientos a cargos de la burocracia federal (1999-2018)}

¿Cuántos son y a qué partidos están afiliados los nominados para los puestos de rango superior y medio de la burocracia federal brasileña? ¿Hay diferencias entre los mandatos presidenciales? Para responder a estas preguntas, construimos una base de datos inédita referente a los afiliados a partidos políticos que ocupan cargos directivos y de asesoramiento superior (DAS). Nuestro análisis descriptivo muestra que la proporción de afiliados aumentó en los gobiernos del Partido de los Trabajadores (PT) y es mayor entre los nominados sin vínculo con el sector público. La concentración de poder entre los partidos - principalmente entre el partido presidencial y los demás-varió de modo significativo entre presidentes. El control del partido sobre los nominados afiliados es más moderado en los cargos de nivel medio y mayor en los rangos superiores. Sin embargo, los afiliados son minoría, incluso en los puestos de mayor poder político-administrativo. Por lo tanto, sugerimos que posiblemente las redes de conexión política que definen a los cuadros de la burocracia decisoria también se construyan por medios extrapartidarios, y comprenderlas es decisivo para dimensionar el peso de la política partidaria en la burocracia ministerial y reinterpretar cómo el Poder Ejecutivo construye y administra la coalición de gobierno y su apoyo en el Poder Legislativo.

Palabras clave: cargos de confianza; nombramientos políticos; burocracia; afiliaciones partidarias; presidencialismo de coalición.

\section{Party filiation and appointment for positions in the Brazilian federal bureaucracy (1999-2018)}

How many are the top and middle-level Brazilian federal bureaucracy appointees, and to which party are they affiliated? Are there differences among presidential mandates regarding the number of these professionals and their party affiliation? This study seeks to answer these questions, by building a new database that gathers the number of party-affiliated public officials that were appointed to Cargos de Direção e Assessoramento Superior (DAS) (position of director and high level consultant). Descriptive analysis found that the proportion of party-affiliated among

O autor Felix Lopez agradece o financiamento da Coordenação de Aperfeiçoamento de Pessoal de Nível Superior (CAPES), sob o Processo 88881.172542/2018-01, durante o período de realização desta pesquisa.

Os autores agradecem as críticas e sugestões dos pareceristas anônimos da Revista de Administração Pública, bem como comentários e sugestões de Frances Hagopian, Alexandre Samy, Antonio Lassance, Alexandre Gomide, Danilo Coelho e Acir Almeida.

Os autores são responsáveis por eventuais omissões e erros neste artigo. 
appointees increased during the Workers' Party (PT) governments and higher among appointed professionals that were not civil servant. The power-sharing among parties - mainly between the party of the president and the others - varies significantly according to the government. The partisan control over appointees is milder in middle-level and stronger at top-level positions. However, a minority of appointees are party members, even among the top-level bureaucracy. Therefore, we suggest that the political networks go beyond the party affiliations. To understand these networks it is necessary to reassess the role of party politics in shaping the executive agenda and enable reinterpretation of how presidents build and manage the government coalition and the support to their agenda in the legislative arena. Keywords: political appointments - Brazil; patronage; political bureaucracy; multiparty presidentialism - Brazil.

\section{INTRODUÇÃO}

A expectativa mais difundida nas análises sobre as nomeações para os cargos de confiança da burocracia federal sugere o domínio de critérios partidários. O que alimenta essa expectativa é a combinação entre regras que permitem a escolha discricionária de milhares de cargos da administração federal direta e indireta e grande número de partidos políticos na arena legislativa ávidos por emplacar seus nomes na burocracia. Como pano de fundo estão os Presidentes da República que, de fato, recorrem às nomeações políticas para construir e gerenciar maiorias legislativas e/ou recompensar aliados (Ames, 1995; Guedes, 1994; Raile, Pereira \& Power, 2011). Pesquisas recentes sobre filiações na burocracia municipal - não federal - fortalecem o argumento de haver conexão partidária relevante entre cargos de confiança e partidos: $1 / 3$ dos servidores municipais são filiados a partidos e parte expressiva se explica pela lógica da patronagem (Barbosa \& Ferreira, 2019).

Em geral, é na mídia que se difundem as imagens de que também há ampla patronagem partidária na gestão federal. As nomeações responderiam a critérios "fisiológicos" para destinar posições a “apadrinhados políticos" e "correligionários" de partidos que "aparelham" o Estado. Embora as menções sejam feitas sem mencionar a filiação formal aos partidos, esta é frequentemente pressuposta. Tal narrativa e seus repertórios terminológicos ecoam na percepção do cidadão e consolidam a imagética que aponta $o$ domínio da razão político-partidária e desapreço pelo mérito na burocracia dirigente federal, cujo perfil dominante seria de pessoas com insuficiente domínio técnico para desempenhar suas funções de gestão.

A literatura especializada, em virtude da ausência de dados detalhados ou sistemáticos sobre as filiações partidárias na burocracia, assume que: a) nomear um ministro partidário confere à legenda direitos exclusivos para escolher os nomes da alta burocracia ministerial; e b) que essas escolhas são predominantemente partidárias. Esse é o caso nas originais análises sobre a relação entre coalizão de governo e apoio legislativo ao presidente, geralmente relacionadas ao debate sobre proporcionalidade partidária na divisão de poder do gabinete de governo (Amorim, 2019; Bertholini \& Pereira, 2017) ${ }^{1}$. Tomando a parte pelo todo, imagina-se que a legenda do ministro de um partido do gabinete definiria as posições de poder infraministeriais. As cadeias de comando do ministro a seus subordinados fluiriam por correias cujos elos se ligam por vínculos partidários comuns².

\footnotetext{
${ }^{1}$ Os corredores do Planalto e do Congresso denominam esses direitos monopolísticos do partido do ministro "porteira fechada".

${ }^{2}$ É o que está implícito, por exemplo, no trecho sublinhado na seguinte consideração: "para formar um governo majoritário no período pós-eleitoral, os presidentes precisam fazer ao menos três escolhas: (1) quantos partidos integrarão a coalizão; (2) quais serão estes partidos e se eles manifestam preferências políticas e ideológicas similares às preferências do Presidente; (3) e a quantidade de poder e recursos que serão partilhados entre os parceiros da coalizão" (Pereira \& Bertholini, 2019, p. 313, grifo nosso, tradução nossa). A análise da divisão do poder partidário no Executivo é importante na literatura sobre o funcionamento do presidencialismo brasileiro porque a divisão equânime tem sido considerada uma estratégia indispensável para o Presidente da República manter apoio legislativo e ampliar a capacidade de implementar a agenda de governo (Amorim, 2000; Mauerberg, 2016; Pereira \& Bertholini, 2019; Raile et al., 2011).
} 
Entretanto, pode ser que a divisão de poder não ocorra dessa forma. Por isso, compreender o real espaço que nomeados com filiação a partidos ocupam na burocracia ministerial dirigente - e as variações por hierarquia funcional, legenda e mandatos, por exemplo - esclarece um pouco mais sobre esse aspecto central do processo de governo: a designação dos quadros da burocracia decisória. Este artigo contribui com o esforço que há décadas tem sido feito para deslindar as regras de operação do presidencialismo multipartidário brasileiro e identificar aspectos importantes do perfil da alta gestão federal. A análise aqui proposta fornece elementos adicionais para esclarecer a complexidade do presidencialismo brasileiro, cuja fragmentação de partidos é alta (Calvo, Guarnieri, \& Limongi, 2015; Mainwaring, 1991), as orientações programáticas das legendas, instáveis, e rotatividade dos nomeados - ministros e burocratas - acima do desejável (Franz \& Codato, 2018; Lopez \& Silva, 2019).

Além da relevância direta no campo dos estudos sobre o sistema político, este artigo dialoga com pesquisas sobre gestão pública - algumas publicadas aqui na Revista de Administração Pública - ao discutir a conexão entre burocracia decisória e política partidária (Cavalcante \& Lotta, 2015; D’Araujo \& Lameirão, 2010; D’Araujo \& Petek, 2018; Pacheco, 2010). Para tanto, descrevemos e analisamos dados sistemáticos sobre filiações partidárias dos nomeados para cargos de confiança da administração pública federal brasileira em 6 diferentes mandatos presidenciais, de 1999 a 2018. Abordamos uma forma específica de politização do setor público - a partidarização. Análises anteriores sobre a politização e a partidarização da alta gestão federal ou utilizam séries anuais mais curtas ou o escopo dos cargos e setores da gestão é menor (D’Araujo \& Lameirão, 2010; D’Araujo \& Petek, 2018; Lopez, 2015; Lopez \& Praça, 2018; Praça, Freitas, \& Hoepers, 2011; Praça \& Lopez, 2019).

Na próxima seção, apresentamos conceitos que norteiam a interpretação dos dados e informações gerais sobre as atribuições e o número de cargos de confiança no Executivo federal brasileiro aqui analisados (denominados cargos de direção e assessoramento superior - DAS). Na seção 3, detalhamos a metodologia para construir os dados. Na seção 4 , analisamos as taxas gerais de filiação do nomeados. $\mathrm{Na}$ seção 5, apresentamos os dados sobre filiações, por partidos e mandatos presidenciais. Na seção 6, discutimos como os resultados ajudam a reconsiderar algumas características pressupostas no presidencialismo brasileiro. E na seção conclusiva resumimos o argumento e elencamos as futuras análises a realizar.

\section{NOMEAÇ̃̃ES PARA CARGOS: POLITIZAÇÃO, PARTIDARIZAÇÃO E PATRONAGEM}

Técnica e política não são termos duais ou autoexcludentes, mas o pêndulo se inclina mais para critérios políticos em cargos com níveis de poder administrativo mais alto, já que a interface com a esfera política se intensifica. Por isso, espera-se maior controle partidário da burocracia decisória de alto escalão em relação aos demais níveis com nomeações também discricionárias. $\mathrm{E}$ razoável que assim seja. Maior proximidade com a política aumenta a responsividade burocrática às preferências dos políticos, em comparação a um quadro burocrático autônomo (Page \& Wright, 1999). Adicionalmente, a autonomia da burocracia de carreira pode tornar mais custoso o desejo de reorientar ações do Estado para as novas demandas resultantes da eleição de um novo governo (Peters \& Pierre, 2004).

Por outro lado, o alto grau de influência política e partidária nos cargos de livre provimento da burocracia é deletério quanto à eficiência das políticas públicas. Razões político-partidárias podem divergir de decisões tecnicamente superiores e impedir sua implementação. Há poucas análises 
sobre implicações da politização da alta burocracia para a implementação das políticas. Entretanto, Lewis (2008) demonstrou que a alta politização das agências aumenta sua ineficiência, embora o mecanismo causal seja a instabilidade decorrente de maior rotatividade de pessoas que não fazem carreira nos órgãos, bem como sua menor experiência de gestão ${ }^{3}$. Gailmard e Patty (2007) sugerem que a combinação entre poderes administrativos para formular políticas públicas de modo mais independente dos políticos e a estabilidade temporal nas posições incentivam a especialização por parte dos burocratas e resultam em melhor desempenho das agências. Esse seria o caso de um regime administrativo que os autores denominam "competências politizadas". Yesilkagit e Van Thiel (2008) sustentam que no caso do sistema administrativo holandês, operando em regime parlamentar, a relação entre autonomia formal das agências e autonomia de facto da influência partidária nas políticas públicas pode ocorrer em sentido contrário ao esperado; agências administrativamente mais independentes podem receber maior influência política. A conclusão evoca as características salientadas por Hammond e Knott (1996) para o caso norte-americano: a autonomia burocrática é contingente em função das estratégias adotadas por cada um dos três supervisores do sistema administrativo norte-americano federal - a Presidência, a Câmara e o Senado.

No Brasil, ainda não temos elementos para analisar as implicações da politização sobre a eficiência no ciclo de gestão das políticas, mas podemos dimensionar a influência partidária em diferentes mandatos e níveis da administração. Neste artigo, apresentamos informações sobre a partidarização dos cargos comissionados federais.

Quando A nomeia B para um cargo DAS-5, os motivos podem ser variados e simultâneos: a simples amizade, a necessidade de retribuir o apoio eleitoral a uma facção política, assegurar que o escolhido exercerá com zelo as atribuições do cargo, estar convicto das capacidades administrativas de B etc. Todos os motivos, legítimos ou não, são passíveis de consideração, pois a escolha é discricionária. Como Grindle (2012), consideramos a natureza discricionária da escolha uma condição suficiente para definir politização e os cargos de confiança são, por natureza, politizados. Desse modo, queremos diferenciar politização e partidarização. A partidarização é uma forma específica de politizar e nada diz se os objetivos são orientados por controle das políticas públicas ou por simples entrega dos cargos como sinecuras (Weber, 2002). Ademais, ao caracterizar politização como uma escolha discricionária, sem conotações normativas, e partidarização como a escolha discricionária de pessoas filiadas a partidos, sem mais, tende-se a evitar noções pré-concebidas - usualmente negativas - entre atributos dos nomeados e qualidade das práticas no exercício da função 4 .

A administração federal brasileira tem cargos de livre provimento nos órgãos da administração direta, indireta - autarquias e fundações - e nas empresas públicas. As empresas públicas estão

\footnotetext{
${ }^{3}$ Para Lewis (2008, p. 196) "sistematicamente, os nomeados políticos obtêm menores pontuações no PART, se comparados aos nomeados vinculados às carreiras dos órgãos. Funcionários federais em agências politizadas são menos propensos a dizer que as respectivas agências são bem gerenciadas ou que são bons lugares para trabalhar. A experiência na agência e maior tempo em posições de gerência explicam por que programas governamentais conduzidos por integrantes das carreiras recebem pontuações maiores. As vantagens que os nomeados políticos tendem a ter sobre os carreiristas em posições de chefia nas agências, tais como escolaridade maior, experiência de gestão no setor privado ou em outros departamentos fora da agência atual, não se correlacionam com desempenho. Experiência no setor público, entretanto, parece contribuir em um aspecto da gestão pública: traduzir orientações políticas em programas com desenho e objetivos claros". O Program Assessment Rating Tool (PART) foi um sistema de gestão que possibilitou atribuir pontos, mensurar e comparar a implementação dos programas conduzidos por cada agência federal norte-americana. O instrumento foi utilizado no governo G. W. Bush e descontinuado a partir do governo B. Obama.

${ }^{4} \mathrm{O}$ conceito de politização é utilizado frequentemente para descrever escolhas baseadas em critérios políticos, sem consideração primordial pela capacidade técnica. Quando isso ocorre, usualmente se fala em patronagem política, clientelismo etc. Nesse sentido, sempre tem assumido conotação pejorativa, pois é difícil identificar a constelação de motivos para as escolhas; não entramos nessa discussão conceitual e remetemos os interessados ao livro de Kopecký, Mair, e Spirova (2012).
} 
excluídas dessa análise porque os cargos têm uma denominação e uma lógica próprias e as informações, quando públicas, não estão acessíveis de modo sistemático. A administração direta e indireta - os ministérios e órgãos vinculados - são politicamente controlados pelo ministro. Abaixo do ministro há o vice-ministro - denominado Secretário Executivo -, cuja maior atribuição é "tocar a máquina ministerial" (Lopez \& Praça, 2015; Pereira, Batista, Praça, \& Lopez, 2017). Em seguida vêm os cargos de DAS - objeto de análise deste artigo.

Os cargos de DAS se dividem em seis níveis hierárquicos, cada um dos quais com atribuições e poder administrativo específicos. Quanto mais alto esse nível e poder, mais frequente é a interface com a esfera política (Gráfico 1). Denominamos médio escalão os níveis 1 a 4 e alto escalão os níveis 5 e 6. Devido à relevância política e administrativa, exploramos, sobretudo, os dados relativos ao alto escalão, que compreende cerca de 1.200 cargos (6\% do total), na média anual da série analisada.

Após aquilo que os órgãos de imprensa denominaram "Escândalo do Mensalão", em 2005, o governo federal promulgou o Decreto n. 5.497 (2005), que passou a exigir cota mínima de 75\% de servidores públicos nomeados para cargos de DAS 1 a 3, 50\% para cargos de DAS-4, mas isentou de cotas os níveis 5 e 6 . Doze anos depois, após reforma administrativa para reduzir o número de órgãos federais, o governo Temer promulgou o Decreto n. 9.021 (2017) e reduziu para 50\% - não mais 75\% - a cota mínima de servidores públicos em cargos de DAS 1 a 3. Para os níveis 5 e 6, antes isentos, definiu-se a cota mínima de $60 \%$ de nomeados vinculados ao setor público, oficializando percentuais médios já observados nas gestões petistas (Lopez, 2015) 5 .

\section{GRÁFICO 1 PERCENTUAL MÉDIO DOS CARGOS DE DAS E ATRIBUIÇÕES, POR NÍVEL HIERÁRQUICO (1999-2018)}

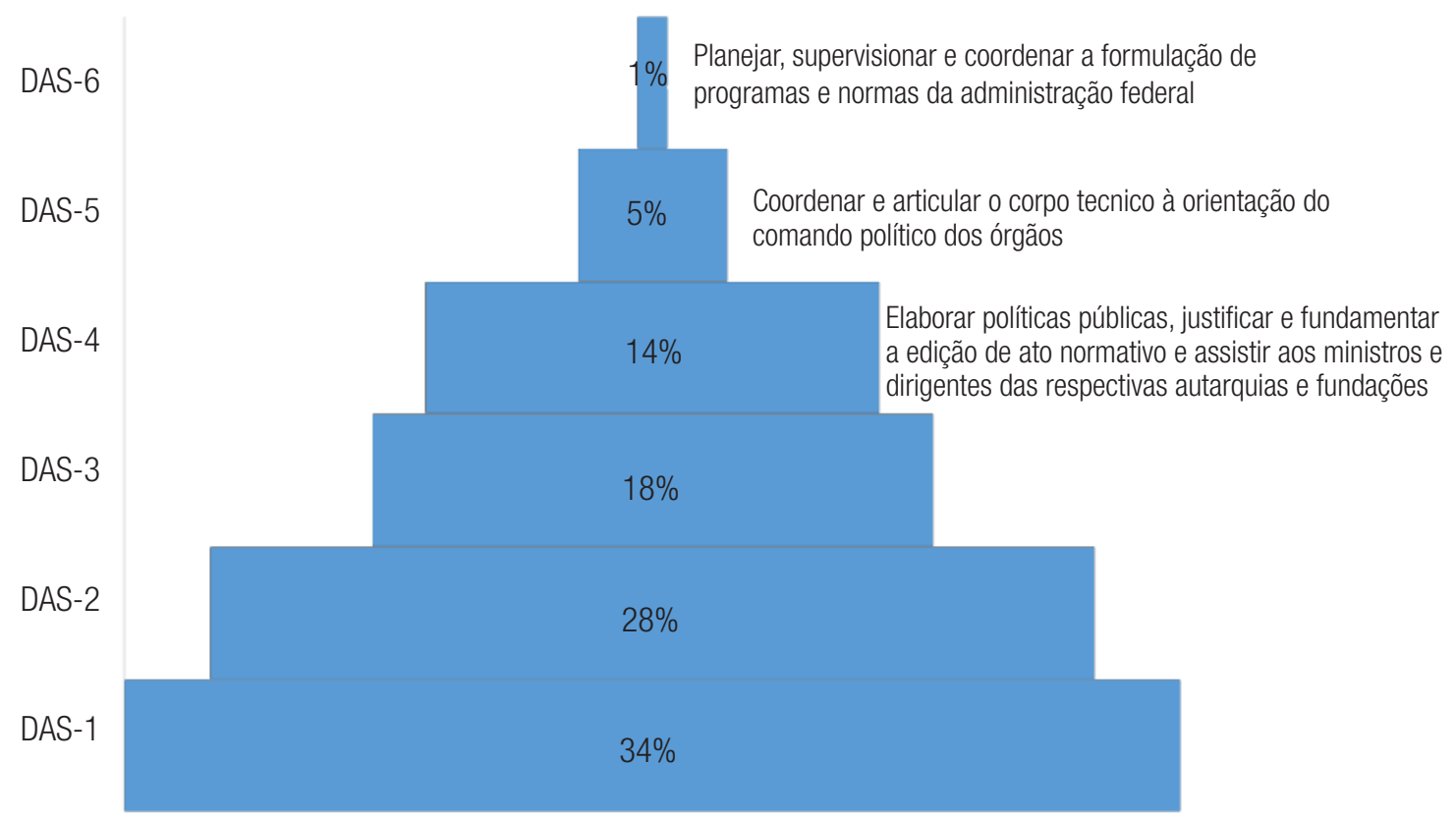

Fonte: Elaborada pelos autores.

\footnotetext{
${ }^{5}$ Referimo-nos ao poder de também indicar. Sabe-se que há, formalmente, a definição de quem oficialmente nomeia, mas o ato oficial mascara o relevante: as negociações que ocorrem nos bastidores, onde se definem quem, de fato, afiança a indicação do nomeado.
} 
Embora com variações ao longo do período aqui explorado, as regras de nomeação seguem, mais ou menos, o seguinte critério geral: para os níveis 1 a 4, os ministros realizam, formalmente, as escolhas e nomeações dos cargos de DAS nos níveis 1 a 4 e, para o alto escalão (níveis 5 e 6), a competência formal é da Casa Civil ou do Presidente da República. Mas houve alterações ao longo do tempo. Por exemplo, no primeiro ano do governo Lula - 2003 -, delegou-se ao Chefe da Casa Civil a prerrogativa para realizar a nomeação oficial de todos os cargos de DAS (níveis 1 a 6). A Casa Civil poderia subdelegar tal competência para os ministros, nos níveis 1 a 4, mas teria "a prerrogativa de intervir nas nomeações em caso de necessidade administrativa" (Lameirão, 2015, p. 189-190, grifo do original).

Saber até onde as nomeações são, de fato, escolhas do ministro, dos partidos do ministro, dos demais integrantes da alta burocracia ou imposições da Casa Civil ou do Presidente da República requer um trabalho arqueológico mais detalhado nos bastidores da política, mas podem ser parcialmente iluminadas pelos dados deste artigo.

Entre 1999 e 2014 houve forte crescimento dos cargos de DAS e redução após esse período, em função das alterações mencionadas (Gráfico 2). O aumento cumulativo do total de postos de DAS no período de 1999 a 2014 foi de 34,6\%, na média da série (Quadro 1), acompanhando o crescimento do número de servidores federais no período (Quadro 2). Após 2015, no entanto, houve redução de $28,4 \%$ dos postos. O Quadro 3 do Gráfico 2 mostra ser pequena variação na proporção de DAS sobre o total dos servidores federais ativos; essa relação nunca superou os $4 \%$. Ou seja, o aumento dos cargos comissionados foi impulsionado pela expansão da força de trabalho no Executivo federal.

Sistemas administrativos quase sempre politizam a alta gestão em algum nível (Kopecký, Mair, \& Spirova, 2012; Kopecký et al., 2016; Peters, 1999; Peters \& Pierre, 2004). As variações nacionais são, em grande parte, tributárias de trajetórias nacionais de desenvolvimento e relacionam-se com diferentes culturas administrativas (Grindle, 2012; Mikkelsen, 2018; Page \& Wright, 1999; Painter \& Peters, 2011; Peters, 1999) ${ }^{7}$. Cada uma delas responde de modo diferente à tensão entre a busca por eficiência, decorrente de um corpo de altos burocratas permanentes e especialistas versus a necessidade de responsividade às mudanças no comando político partidário do Estado ou das agências públicas (Page \& Wright, 1999).

$\mathrm{Na}$ administração federal brasileira, essa fronteira entre o campo de influência direta da política, dos partidos e dos parlamentares é turva e móvel. Há um espaço de indefinição no qual a política e a administração, a preferência ideológico-partidária do gestor e a capacidade técnica para executar as decisões inerentes aos cargos se tornam indistinguíveis. A rotatividade dos cargos é uma forma de observar a conexão entre política e administração. A administração federal apresenta taxa anual de rotatividade dos cargos de DAS de aproximadamente 30\%, embora existam variações importantes nos anos que seguem a eleição presidencial (Lopez, M. Bugarin, \& K. Bugarin, 2015). A rotatividade dos nomeados cai a partir do segundo ano de governo e tem novo pico no início de cada mandato. As mudanças de partido no controle do ministério ampliam em aproximadamente $20 \%$ a rotatividade no ministério; após mudanças faccionais - quando se muda o ministro, mas não o partido no comando da pasta -, a rotatividade aumenta em 11\% (Lopez et al., 2015). A alta instabilidade dos cargos de livre provimento também se manifesta pelo tempo de sobrevivência mediana de 25 e 23 meses nos cargos de DAS do médio e alto escalão, respectivamente (Lopez \& Silva, 2019).

\footnotetext{
${ }^{6}$ A evolução institucional dos direitos de nomeação do governo Fernando Henrique Cardoso (FHC) ao governo Dilma Rousseff foi explorada em detalhe por Lameirão (2011a, 2013, 2015) e D’Araújo e Lameirão (2011).

${ }^{7}$ Painter e Peters (2011) identificam 9 diferentes tradições administrativas, que ajudam a compreender legados persistentes - embora cambiantes - de modos de organizar as agências de Estado e dividir seu poder administrativo.
} 
RAP | Filiações partidárias e nomeações para cargos da burocracia federal (1999-2018)

\section{GRÁFICO 2 EVOLUÇÃO DO NÚMERO DE CARGOS DE DAS (1999-2018)}

Número total de cargos DAS, por ano (1999-2018)

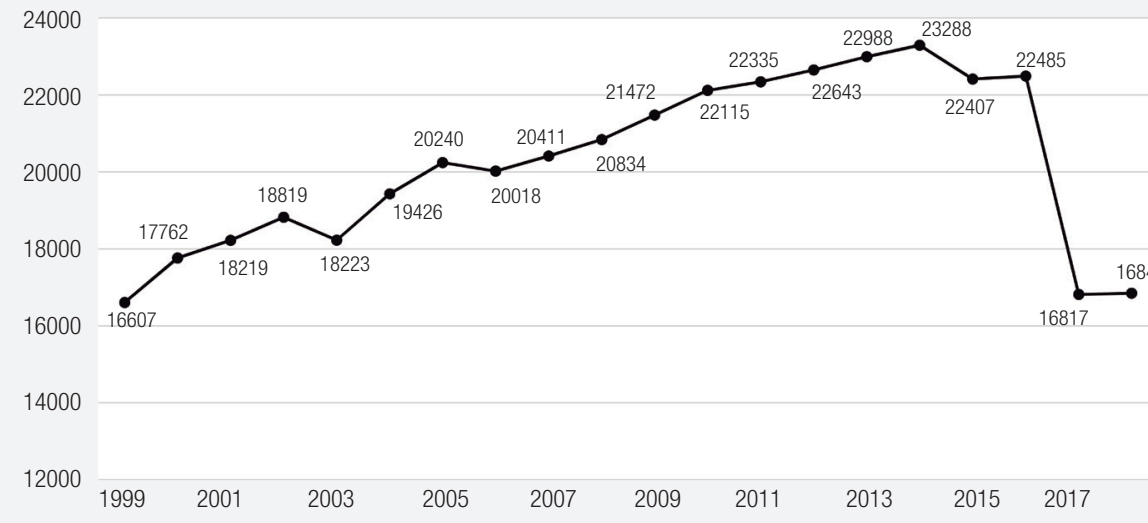

Total de servidores civis federais ativos, por ano (1999-2018)

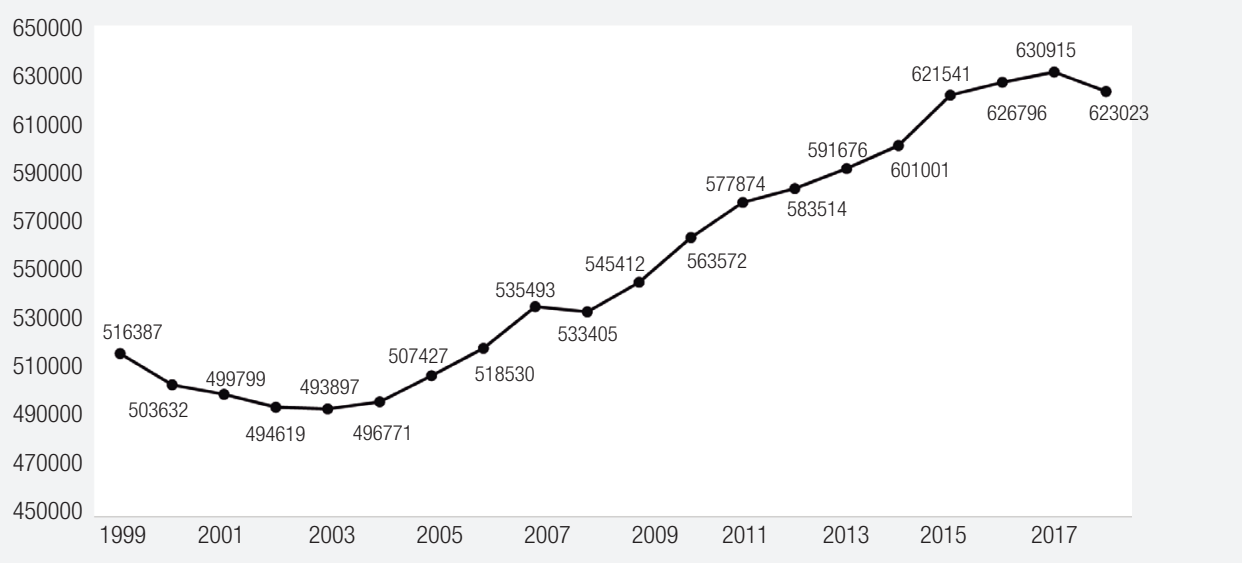

Percentual do total de cargos de DAS em relação ao total de servidores federais ativos (1999-2018)

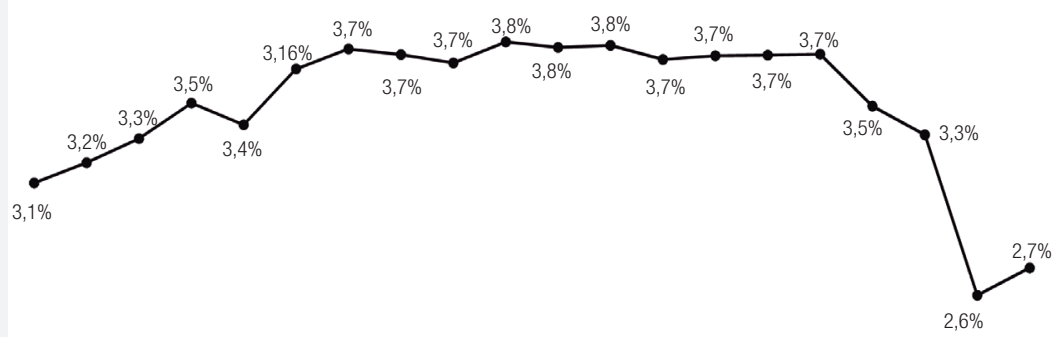

19992000200120022003200420052006200720082009201020112012201320142015201620172018

Fonte: Elaborado pelos autores. 
Por essa métrica da rotatividade e da sobrevivência nos cargos, vê-se que a influência política sobre a burocracia é maior nos níveis mais altos da gestão (Lopez et al., 2015; Lopez \& Praça, 2015). Contribui para tanto, além do já mencionado poder administrativo, a remuneração e prestígio associado aos cargos de níveis mais altos, que tornam esses postos mais convidativos para pessoas de fora do setor público.

Um passo adicional para compreender a relação da política partidária com a alta gestão pode ser dado com dados sobre as filiações. Em que medida os governos recrutam filiados para os cargos de DAS? Esse recrutamento varia por nível ou entre governos? Quais partidos recrutam mais filiados? O recrutamento está circunscrito aos partidos da coalizão?

Nas próximas seções, analisamos a construção dos dados e as respostas a essas questões.

\section{DADOS E MÉTODOS}

O método adotado é descritivo (Gerring, 2012) e propõe apresentar alguns indicadores e tendências referentes à partidarização na burocracia. Os dados foram extraídos do Sistema de Administração de Pessoal da Administração Federal (SIAPE) e da lista nacional de filiados a partidos políticos disponível no site do Tribunal Superior Eleitoral (TSE, n.d.).

Do SIAPE, utilizamos o número do título de eleitor dos servidores federais, disponível a partir de $2014^{8}$. Na base do TSE (n.d.), coletamos os dados relativos aos filiados a partidos políticos, a data e a legenda de filiação e o número do título de eleitor. Desse modo, a partir de 2014 há uma chave única segura da informação dos servidores nomeados para cargos de DAS filiados: o número do título eleitoral. Tal chave tornou possível resolver de modo consistente o problema das pessoas homônimas filiadas, entre 2014 e $2018^{9}$. Nos anos anteriores, combinamos as bases do SIAPE com os dados de filiação a partir dos nomes dos servidores e dos filiados. Em ambos os períodos, obtivemos uma taxa de filiação semelhante, em torno de $12 \%$ dos funcionários de DAS.

A questão dos filiados homônimos no período de 1999 a 2013 foi resolvida adotando-se o seguinte procedimento: utilizamos os dados do título de eleitor referentes aos anos de 2014 a 2018 do universo dos servidores federais para identificar se homônimos no banco do TSE eram ou não servidores federais. Para os casos residuais remanescentes, verificamos se a unidade federativa de filiação era a mesma ou da unidade federativa do local onde o órgão federal se situava, caso em que assumimos se tratar de pessoa vinculada ao setor público federal. O critério não pode ser aplicado aos servidores homônimos sem vínculo com o setor público, mas como estes representam a imensa minoria dos ocupantes de DAS, as alterações são apenas residuais. Os anos de 2014 a 2018 serviram como validação externa para a decisão de não incluirmos todos os homônimos de maneira indiscriminada e, desse modo, evitar que os valores percentuais de filiados fossem, a nosso ver, incorretamente inflados. Adotando esse critério, construímos uma base de dados que coincide com o ano de início da disponibilização dos dados dos servidores no SIAPE (1999-2018), o que possibilita análises mais abrangentes. Para todos os casos, considerou-se o controle usual de verificar se a filiação partidária

\footnotetext{
${ }^{8}$ Essa informação não consta em bancos de dados públicos e é de acesso restrito ao então Ministério do Planejamento Desenvolvimento e Gestão. Os dados foram utilizados como parte de projetos de cooperação entre MPDG e IPEA, que se encontra administrativamente vinculado a esse ministério.

${ }^{9}$ A questão dos homônimos foi discutida também por Praça, Freitas, e Hoepers (2011) e Barbosa e Ferreira (2019).
} 
antecedia a nomeação ao cargo. Nos registros do TSE (n.d.), excluímos os casos que constavam como filiação "cancelada", "desfiliada" e "sub judice"; 77\% estavam em situação regular e os demais constavam como "cancelados" (21\%), "desfiliados" (2\%) e outros (0,4\%).

\section{AS FILIAÇÕES E OS CARGOS DE CONFIANÇA - DIREÇÃO E ASSESSORAMENTO SUPERIOR}

Esta seção apresenta informações longitudinais e detalha argumentos mais gerais formulados em Lopez e Praça $(2018)^{10}$. No universo de 421 mil cargos de DAS - de 1999-2018 -, os nomeados filiados a partidos constituíam $13 \%$ do total, superior aos $8 \%$ observados na população brasileira estimada, que em 2015 contava com 16,5 milhões de filiados a partidos políticos. Esse percentual sugere que não é predominantemente por meio da filiação formal que os vínculos partidários dos nomeados para cargos de confiança federais, se existem, manifestam-se. Mas o percentual varia significativamente por nível hierárquico e vai de $12 \%$ e $11 \%$, nos níveis mais baixos (DAS 1 a 3), a 28\% no nível mais alto (DAS-6) (Gráfico 3) ${ }^{11}$.

\section{GRÁFICO 3 PERCENTUAL OCUPANTES DE CARGOS DAS FILIADOS A PARTIDOS, POR NÍVEL HIERÁRQUICO DO CARGO (1999-2018)}

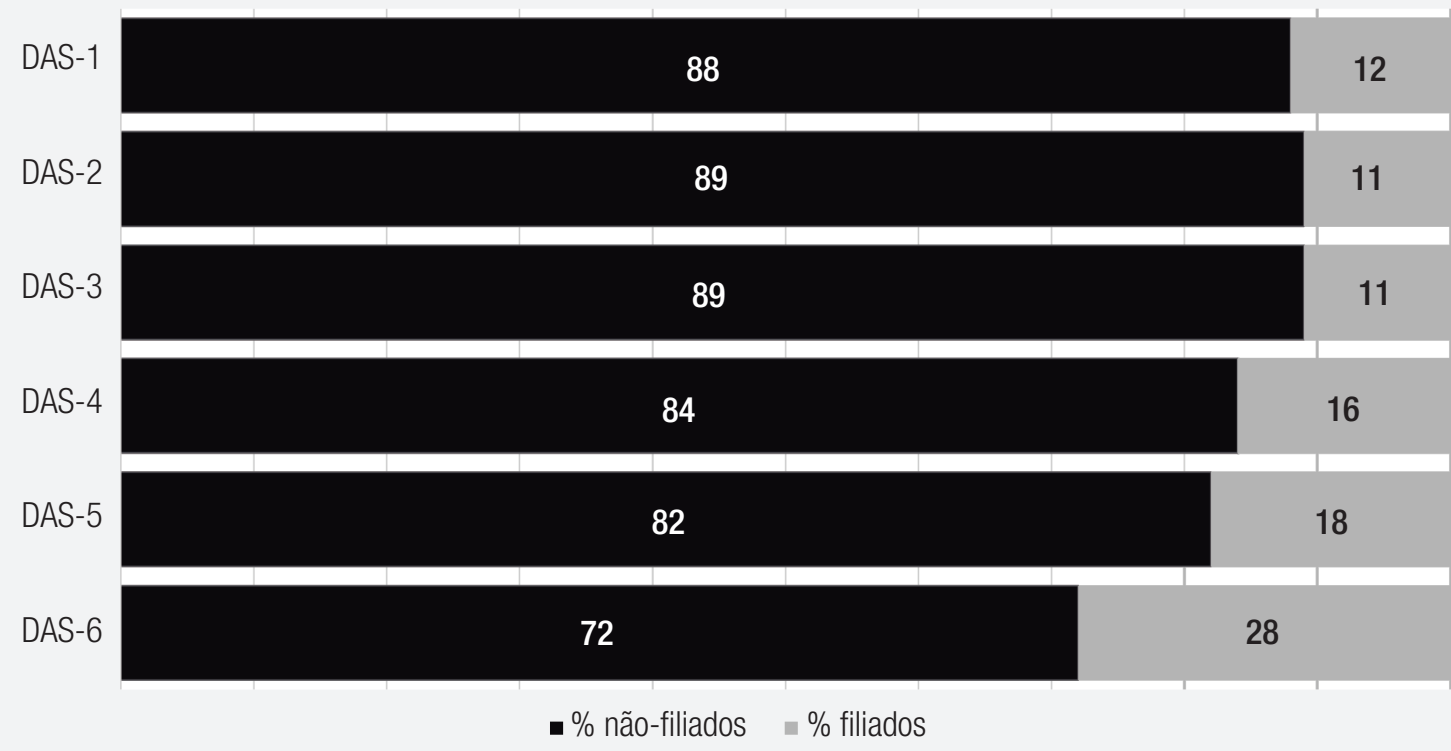

Fonte: Elaborado pelos autores.

\footnotetext{
${ }^{10}$ Uma análise sobre diferenças observadas entre áreas de políticas públicas ou ministérios será objeto de análise em outro texto. ${ }^{11}$ Os percentuais são próximos aos reportados por Barberia e Praça (n.d.), que apontam uma taxa geral de filiação de $12 \%$ nos ocupantes de cargos de DAS durante o ano de 2010.
} 
A taxa de filiação dos nomeados sem vínculo com o setor público é significativamente maior, principalmente nos níveis 5 e 6 (Gráfico 4). Nos DAS-5, os servidores vinculados ao setor público e filiados correspondiam a $9 \%$, percentual que sobe para $27 \%$ e entre os nomeados sem vínculo, no mesmo nível hierárquico. Entre os cargos de DAS-6, os percentuais de filiação são de $12 \%$ entre servidores e $35 \%$ entre os nomeados sem vínculo com o setor público. Houve marcada ampliação nessa diferença a partir de 2003, quando se iniciam as presidências do Partido dos Trabalhadores (PT), e que se manteve durante o governo Temer (Gráfico 4).

Diversos motivos podem explicar a diferença na intensidade na filiação entre servidores com e sem vínculo no setor público. O mais importante a destacar é que os cargos de alto escalão gozam de maior trânsito com a esfera política e são mais cobiçados por exercerem maior controle sobre as políticas públicas e influenciarem decisões relevantes ${ }^{12}$. Em geral, o que o Gráfico 4 revela é que a gestão é menos partidarizada quando os cargos são ocupados por servidores de carreira ${ }^{13}$.

Cabe ressaltar que o crescimento da proporção de filiados a partir das presidências do PT também foi acompanhado por expansão do percentual de servidores de carreira em cargos de alto escalão (Lopez, 2015). Em outros termos, aumentou o percentual de filiados a partidos, especialmente os nomeados de fora do setor público, mas também aumentou a profissionalização nos cargos de DAS.

O terceiro aspecto - retratado pela linha intermediária do Gráfico 4 - é que as fontes da politização estão fora do círculo de pessoas oficialmente filiadas. Na próxima seção, discutimos os vínculos partidários por mandatos e legendas.

\footnotetext{
${ }^{12}$ Cargos de níveis mais altos também são um prêmio mais alto para servidores ou correligionários: pagam mais, têm mais poder, têm mais prestígio.

${ }_{13}$ As diferenças entre servidores e não servidores e o fato da maioria dos nomeados em postos de alto escalão não ter vínculos formais com partidos não exime, necessariamente, os servidores públicos de atuarem por motivações partidárias e desempenham atividades políticas. Essa possibilidade é que confere aos líderes políticos oportunidades de pinçar de dentro das carreiras públicas pessoas mais afinadas com suas preferências. Aqui, entretanto, entraríamos em uma discussão adicional sobre a relação entre carreiras, filiações e neutralidade burocrática, que não cabe realizar neste momento.
} 


\section{GRÁFICO 4 PERCENTUAIS DE FILIADOS A PARTIDOS POLÍTICOS EM CARGOS DE DAS-5 E DAS-6, POR TIPO DE VÍNCULO COM $O$ SETOR PÚBLICO (1999-2018) E TOTAL DE FILIADOS}

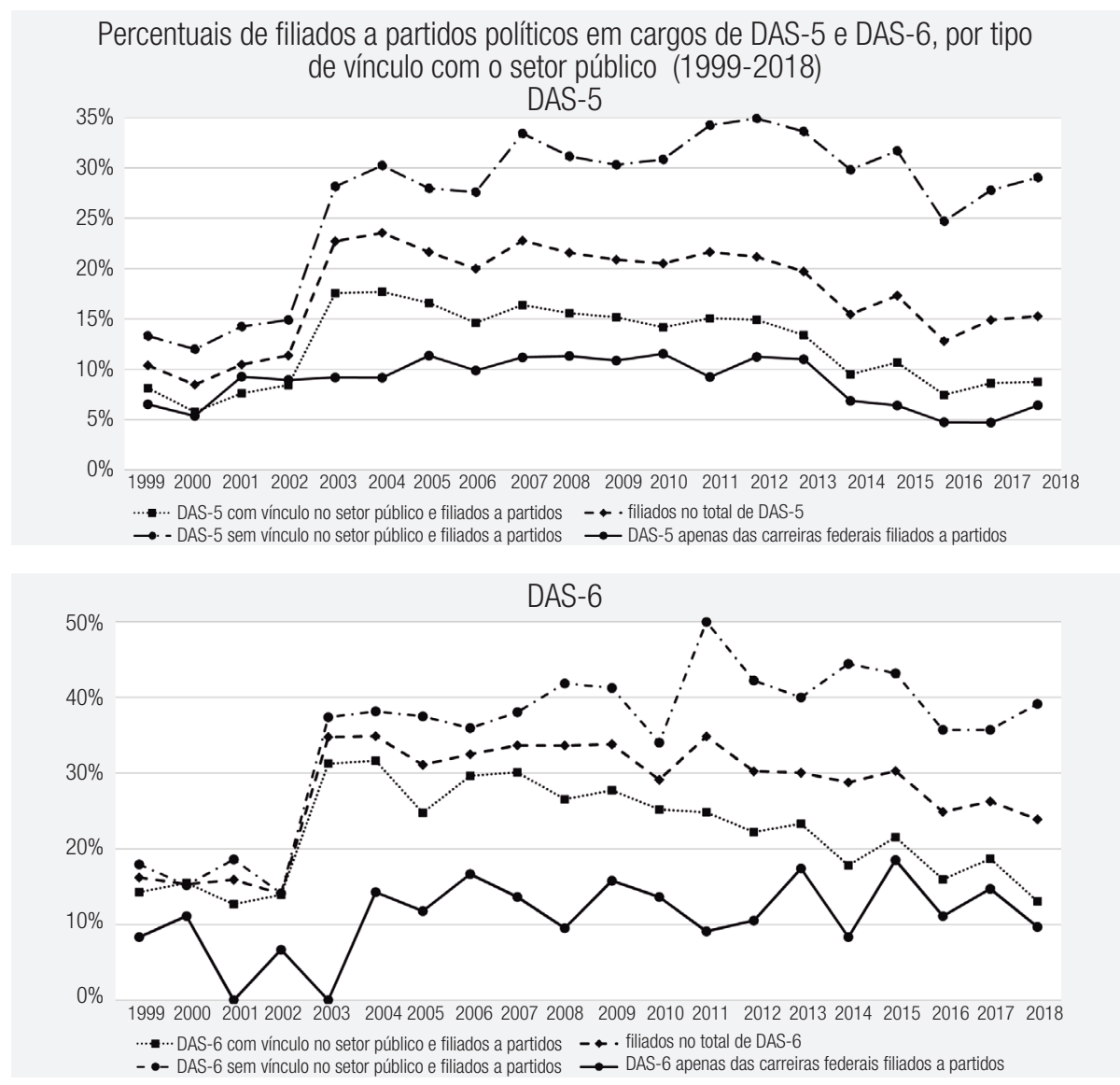

Fonte: Elaborado pelos autores.

Nota: o rótulo "apenas carreiras federais" refere-se aos servidores federais ativos e exclui servidores de outros níveis administrativos ou empresas públicas. O rótulo "com vínculo no setor público" refere-se à categoria ampla de servidores vinculados ao setor público, entre os quais os servidores estaduais e municipais eventualmente cedidos ou requisitados para a administração federal, servidores oriundos de empresas públicas, aposentados e outros. Adotamos a distinção entre os dois grupos porque ela aponta que quanto mais restrito às carreiras federais ativas, menores são os percentuais médios de filiados.

\section{FILIAÇÕES, LEGENDAS E MANDATOS}

As taxas de filiação variam entre mandatos. Em todos os níveis - de 1 a 6 - é visível a elevação do percentual de filiados a partir da gestão do PT. Nos DAS 5 e 6, a proporção de filiados dobrou, se comparada à média do primeiro mandato Lula com a média do segundo mandato Fernando Henrique Cardoso (FHC) ${ }^{14}$.

\footnotetext{
${ }^{14}$ Nogueira e Cardoso (2011) apontam a presença relevante de consultores contratados por meio de agências internacionais no governo FHC. Muitas vezes, esses consultores desempenham funções equivalentes e substitutas de DAS de alta gestão. É preciso cautela, portanto, ao presumir que o valor relativo de DAS no conjunto das posições de poder nos ministérios - ou alguns deles - seja estável, também porque houve recomposição salarial desses cargos a partir de 2003, já durante o governo Lula.
} 
Entre as gestões Lula e Dilma não houve diferença significativa nas taxas de filiação (Tabela 1), embora tenha ocorrido crescimento expressivo entre os nomeados de fora do setor público, com picos em 2003 e 2011 (Gráfico 4, seção anterior).

\section{TABELA 1 PERCENTUAL DE FILIADOS EM CARGOS DE DAS, POR MANDATO E NÍVEL HIERÁRQUICO} (1999-2018)

\begin{tabular}{|c|c|c|c|c|c|c|c|c|c|c|c|c|}
\hline Mandato & $\begin{array}{c}\text { Total } \\
\text { DAS-1 }\end{array}$ & $\begin{array}{c}\% \\
\text { DAS-1 } \\
\text { filiados }\end{array}$ & $\begin{array}{c}\text { Total } \\
\text { DAS- } \\
2\end{array}$ & $\begin{array}{c}\% \\
\text { DAS-2 } \\
\text { filiados }\end{array}$ & $\begin{array}{c}\text { Total } \\
\text { DAS- } \\
3\end{array}$ & $\begin{array}{c}\% \\
\text { DAS-3 } \\
\text { filiados }\end{array}$ & $\begin{array}{c}\text { Total } \\
\text { DAS- } \\
4\end{array}$ & $\begin{array}{c}\% \\
\text { DAS-4 } \\
\text { filiados }\end{array}$ & $\begin{array}{c}\text { Total } \\
\text { DAS-5 }\end{array}$ & $\begin{array}{c}\% \\
\text { DAS-5 } \\
\text { filiados }\end{array}$ & $\begin{array}{c}\text { Total } \\
\text { DAS- } \\
6\end{array}$ & $\begin{array}{c}\% \\
\text { DAS-6 } \\
\text { filiados }\end{array}$ \\
\hline FHC $\|$ & 11170 & $9 \%$ & 8662 & $8 \%$ & 4029 & $8 \%$ & 2758 & $10 \%$ & 946 & $10 \%$ & 205 & $15 \%$ \\
\hline Lula I & 11424 & $12 \%$ & 8207 & $11 \%$ & 4859 & $12 \%$ & 3805 & $17 \%$ & 1192 & $22 \%$ & 256 & $33 \%$ \\
\hline Lula II & 11464 & $13 \%$ & 9002 & $12 \%$ & 5604 & $13 \%$ & 4318 & $17 \%$ & 1251 & $21 \%$ & 243 & $33 \%$ \\
\hline Dilma I & 11909 & $14 \%$ & 9653 & $13 \%$ & 6157 & $13 \%$ & 4979 & $18 \%$ & 1421 & $19 \%$ & 305 & $31 \%$ \\
\hline Dilmall & 7172 & $11 \%$ & 6123 & $9 \%$ & 4182 & $9 \%$ & 3539 & $16 \%$ & 1089 & $17 \%$ & 215 & $30 \%$ \\
\hline Temer & 9530 & $12 \%$ & 8159 & $11 \%$ & 4908 & $10 \%$ & 4363 & $15 \%$ & 1531 & $14 \%$ & 300 & $25 \%$ \\
\hline
\end{tabular}

Fonte: Elaborada pelos autores.

Nota: Os dados se referem aos ocupantes de cargos de DAS do mês de dezembro, em cada ano. Por esse motivo, para o governo Dilma II, considerou-se apenas o ano de 2015 e atribuiu-se o ano de 2016 ao governo Temer, que assumiu interinamente a Presidência da República em maio e, oficialmente, em agosto de 2016. Embora em dezembro de 2016 a transição de nomes da alta gestão ainda pudesse estar em curso, a maior parte já fora concluída.

A estratégia de partilha do poder na burocracia política diferiu entre as presidências do PSDB, PT e PMDB. No segundo governo FHC, as taxas de filiação são mais distribuídas entre os partidos da coalizão, sobretudo ${ }^{15}$. PSDB e PMDB detiveram 31\% e 25\% de DAS filiados. Mas o Democratas (antigo PFL) e o PP (antigo PPB) tinham, respectivamente, 10\% e 6\% dos filiados no alto escalão percentuais inferiores ao PT, à época, na oposição.

Nos governos Lula e Dilma, os filiados integrantes da alta burocracia se concentram no PT. Nos cargos de DAS 5 e 6, entre os nomeados filiados a partidos, o percentual varia entre $39 \%$ de filiados ao PT, no segundo mandato de Lula, e alcança 53\% no segundo mandato de Dilma. Para além da constatação de que o PT concentrou poder político na divisão das pastas ministeriais (Bertholini \& Pereira, 2017; Praça, Freitas, \& Hoepers, 2011), também se observa concentração nos postos da alta burocracia ${ }^{16}$. Essa concentração foi objeto de crítica dos parceiros da coalizão, em diferentes

\footnotetext{
${ }^{15}$ PMDB, PSDB, Democratas e PP - à época PPB (Nexo, 2018) - integraram o gabinete. O Democratas (à época PFL) saiu do gabinete em março de 2002 (Almeida, 2018). Espera-se que a média menor do PFL reflita esse ano fora do quarto ano do segundo mandato de FHC, pois os dados sobre DAS se referem ao mês de dezembro de cada ano. Agradecemos ao pesquisador do Ipea Acir Almeida, por disponibilizar o banco de dados sobre partidos da coalizão e partidos do gabinete.

${ }^{16} \mathrm{O}$ gabinete - cujo número de partidos é usualmente menor do que o número de partidos que integram a coalizão parlamentar - do primeiro mandato Lula foi composto pelos seguintes partidos: PT, PL, PC do B, PSB, PTB, PDT, PPS e PV. Ainda em 2003, o PDT deixou o gabinete. O PPS ingressou no gabinete. No início de 2004, o PMDB ingressou no gabinete. No primeiro ano do segundo mandato, o gabinete Lula estava composto por PT-PR-PC do B-PSB-PTB-PMDB-PP-PDT-PV. Em 2010, o PV deixou o gabinete. O gabinete do primeiro ano do governo Dilma, em 2011, era formado pelos seguintes partidos: PT, PR, PC do B, PSB, PMDB, PP e PDT. Em 2012, o PRB ingressou no gabinete e o PSB o deixou. No primeiro ano do segundo mandato Dilma, 2015, o gabinete foi composto pelos seguintes partidos: PT, PR, PC do B, PMDB, PP, PDT, PRB, PROS, PSD e PTB. O governo Temer montou seu gabinete com os seguintes partidos: PMDB, PSDB, DEM, PP, PR, PSD, PTB, PRB, PSB e PPS (Almeida, 2018).
} 
momentos ${ }^{17}$. No governo Temer, a desconcentração volta a ocorrer, embora tendo o PMDB com o maior percentual de filiados (26\%, conforme a Tabela 2$)$.

\section{TABELA 2 NÚMERO E PERCENTUAL DE NOMEADOS FILIADOS A PARTIDOS, EXCLUINDO-SE OS SERVIDORES SEM FILIAÇÃO - PARA OS CARGOS DE DAS 5 E 6, POR MANDATO PRESIDENCIAL (1999-2018)}

\begin{tabular}{|c|c|c|c|c|c|c|c|c|}
\hline \multicolumn{3}{|c|}{ FHC II } & \multicolumn{3}{|c|}{ Lula I } & \multicolumn{3}{|c|}{ Lula II } \\
\hline Partido & $\mathrm{N}$ filiados & $\%$ filiados & Partido & $\mathrm{N}$ filiados & $\%$ filiados & Partido & $\mathrm{N}$ filiados & $\%$ filiados \\
\hline PSDB & 51 & $31 \%$ & PT & 275 & $65 \%$ & PT & 236 & $57 \%$ \\
\hline MDB & 41 & $25 \%$ & MDB & 34 & $8 \%$ & MDB & 44 & $11 \%$ \\
\hline PT & 22 & $13 \%$ & PSDB & 24 & $6 \%$ & PSDB & 28 & $7 \%$ \\
\hline DEM & 16 & $10 \%$ & $P C$ do $B$ & 15 & $4 \%$ & PDT & 18 & $4 \%$ \\
\hline PDT & 11 & $7 \%$ & PSB & 14 & $3 \%$ & $P C$ do $B$ & 15 & $4 \%$ \\
\hline PP & 10 & $6 \%$ & PPS & 12 & $3 \%$ & PP & 13 & $3 \%$ \\
\hline PTB & 4 & $2 \%$ & PDT & 10 & $2 \%$ & PSB & 13 & $3 \%$ \\
\hline PPS & 3 & $2 \%$ & PTB & 9 & $2 \%$ & DEM & 10 & $2 \%$ \\
\hline PR & 2 & $1 \%$ & PP & 8 & $2 \%$ & PTB & 10 & $2 \%$ \\
\hline PSB & 2 & $1 \%$ & DEM & 6 & $1 \%$ & PPS & 7 & $2 \%$ \\
\hline Outros & 2 & $1 \%$ & Outros & 5 & $1 \%$ & Outros & 6 & $1 \%$ \\
\hline \multicolumn{3}{|c|}{ Dilma I } & \multicolumn{3}{|c|}{ Dilma II } & \multicolumn{3}{|c|}{ Temer } \\
\hline Partido & $\mathrm{N}$ filiados & $\%$ filiados & Partido & $\mathrm{N}$ filiados & $\%$ filiados & Partido & $\mathrm{N}$ filiados & $\%$ filiados \\
\hline PT & 248 & $53 \%$ & PT & 142 & $56 \%$ & MDB & 89 & $26 \%$ \\
\hline MDB & 55 & $12 \%$ & MDB & 35 & $14 \%$ & PSDB & 42 & $12 \%$ \\
\hline PSDB & 23 & $5 \%$ & $P C$ do $B$ & 13 & $5 \%$ & PT & 25 & $7 \%$ \\
\hline PDT & 22 & $5 \%$ & PDT & 12 & $5 \%$ & PSB & 20 & $6 \%$ \\
\hline PSB & 21 & $4 \%$ & PSDB & 7 & $3 \%$ & PP & 19 & $5 \%$ \\
\hline$P C$ do $B$ & 20 & $4 \%$ & PP & 6 & $2 \%$ & PPS & 19 & $5 \%$ \\
\hline DEM & 18 & $4 \%$ & PRB & 6 & $2 \%$ & DEM & 18 & $5 \%$ \\
\hline PP & 16 & $3 \%$ & PSB & 6 & $2 \%$ & PDT & 13 & $4 \%$ \\
\hline PTB & 10 & $2 \%$ & DEM & 5 & $2 \%$ & PV & 13 & $4 \%$ \\
\hline PPS & 5 & $1 \%$ & PSD & 5 & $2 \%$ & PRB & 12 & $3 \%$ \\
\hline Outros & 5 & $1 \%$ & Outros & 3 & $1 \%$ & Outros & 12 & $3 \%$ \\
\hline
\end{tabular}

Fonte: Elaborada pelos autores.

${ }^{17}$ A nosso ver, contudo, as implicações dessa concentração podem ser diversas. Por um lado, gera insatisfação política dos aliados; por outro, pode ser um meio do presidente melhorar a coordenação no ciclo das políticas setoriais, em meio à fragmentação partidária e faccional. 
A maioria dos nomeados filiados pertenciam a partidos de situação tanto nos DAS 1 a 4 quanto nos DAS 5 e 6 - exceto no governo FHC II, no qual a oposição ocupava mais postos no médio escalão (Gráfico 5). Mesmo nos mandatos do PT, em que se observou maior concentração de filiados da legenda, o acesso de filiados a partidos da oposição passa de 30\% dos cargos de DAS 1 a 4 no período considerado - exceto em Lula II (26\%). No alto escalão, filiados da oposição controlaram, em média, 15\% dos postos nos mandatos petistas, enquanto somaram 36\% e 28\% em FHC II e Temer, respectivamente (Gráfico 5).

Se consideramos que a maioria dos nomeados não é filiada, resulta que uma fração pequena dos cargos do alto escalão é ocupada por filiados a partidos da oposição, em valores que estão sempre abaixo de $10 \%$ do total (Gráfico 5A).

Em geral, quanto menor o nível hierárquico, maior é a diversidade e proporção de filiados de partidos de fora do gabinete (Gráfico 5). Nos cargos de alto escalão, a diversidade se restringe aos partidos da coalizão ou nomeados sem filiação. A diversidade maior de partidos no médio escalão, somadas ao fato de os nomeados filiados constituírem minoria sugerem que os controles partidários de acesso ao poder burocrático não são estritos, embora orientem uma parte importante das escolhas.

O fato de filiados a partidos de fora do gabinete - da oposição, inclusive - assumirem ou permanecerem em seus cargos em parte se explica pela experiência de servidores no desempenho de funções específicas. Os microdados revelam que alguns nomeados filiados a um mesmo partido atravessam incólumes as mudanças de gestão durante os mandatos presidenciais de partidos rivais no plenário da Câmara.

\section{GRÁFICO 5 PERCENTUAL DE NOMEADOS PARA CARGOS DE DAS FILIADOS A PARTIDOS DA COALIZÃO E DE FORA DA COALIZÃO, NO TOTAL DE FILIADOS, POR GRUPOS HIERÁRQUICOS (1999-2018)}

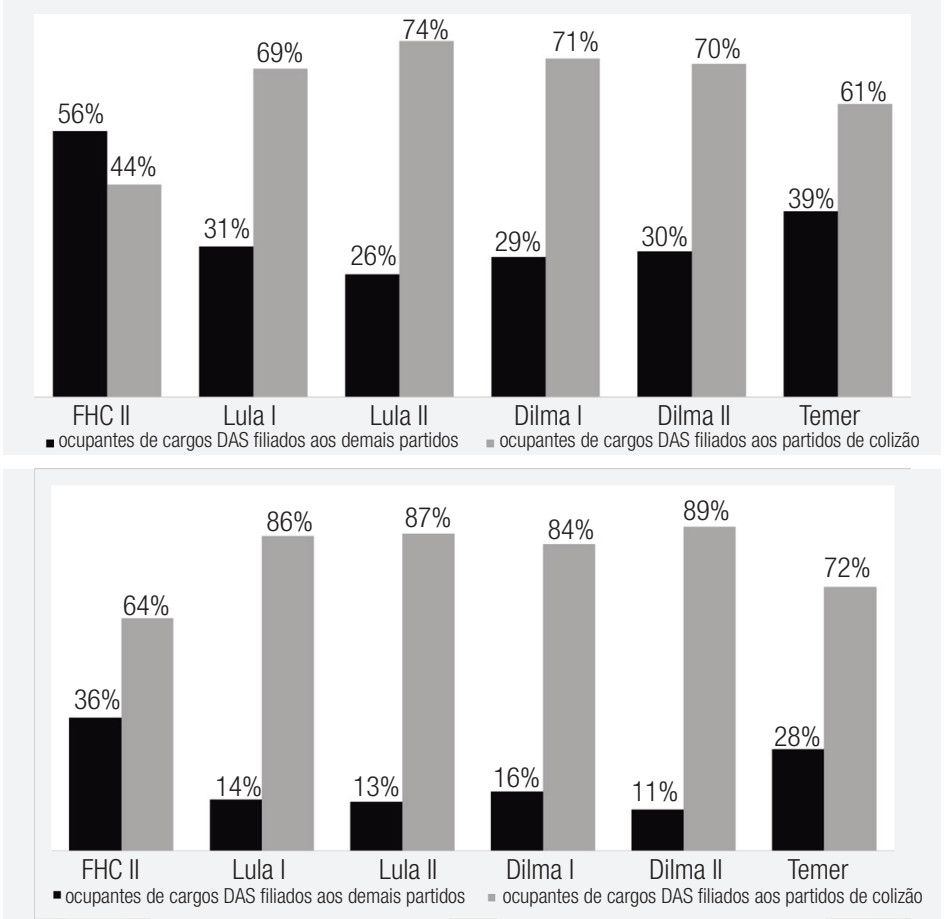

Fonte: Elaborada pelos autores. 


\section{GRÁFICO 5A PROPORÇÃO DE NÃO FILIADOS, FILIADOS A PARTIDOS DA SITUAÇÃO E DA OPOSIÇÃO NOS CARGOS DE DAS, POR GRUPOS HIERÁRQUICOS (1999-2018)}

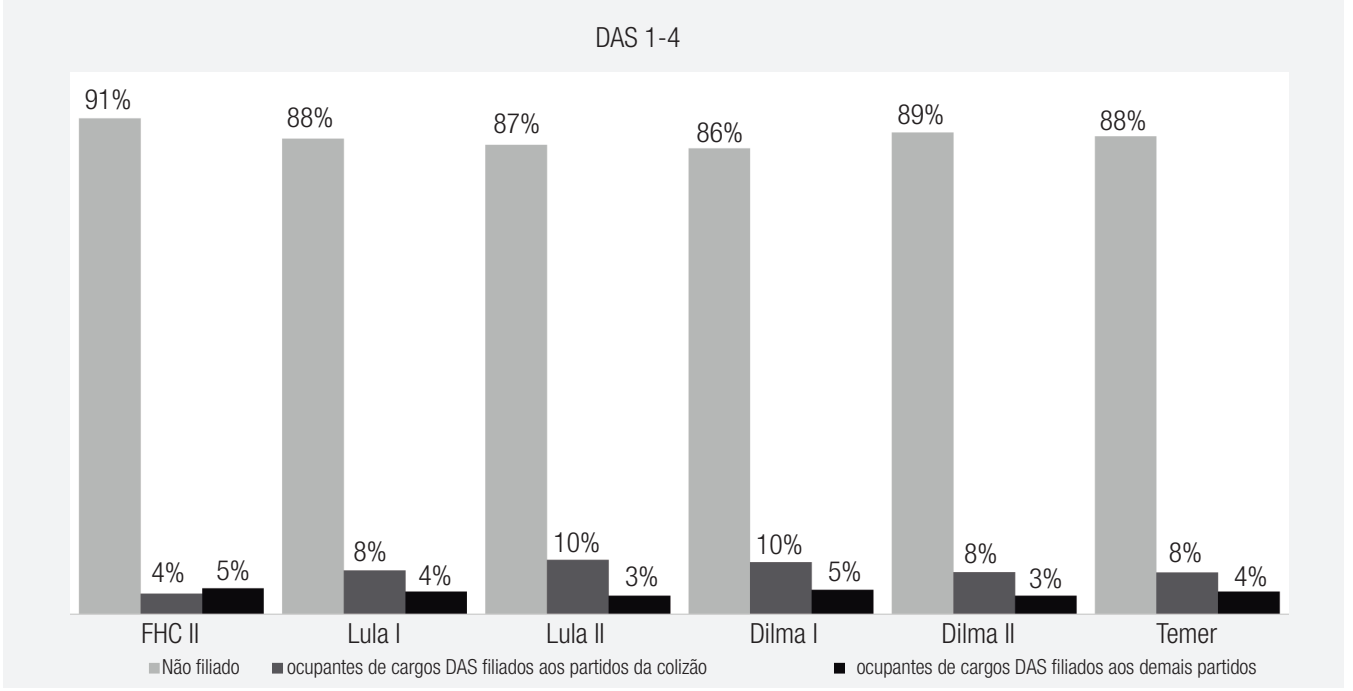

DAS 5-6

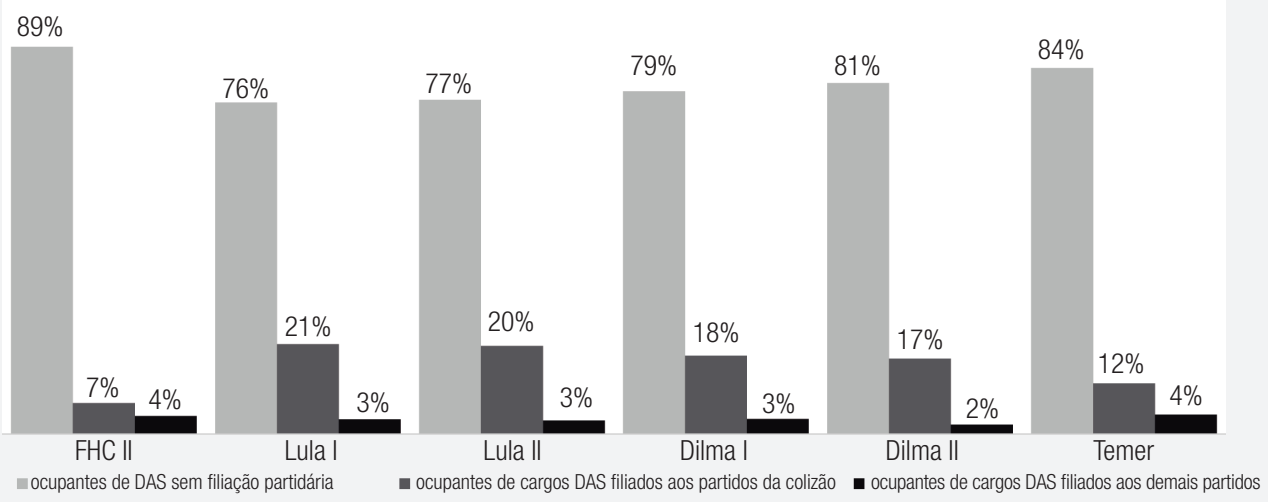

Fonte: Elaborada pelos autores.

A diversidade de legendas no médio e alto escalão - e o crescimento do número de legendas entre os filiados no médio escalão - também se expressa pelo fato de, na série de 19 anos, o número médio de legendas partidárias com filiados ser de 28 , no médio escalão, e de 18 , no alto escalão. No médio escalão, o número absoluto quase sempre oscilou acima de 20 e incluiu agremiações sem representação legislativa; no alto escalão, o número de legendas passou de 12, em 1999 para 28, em 2018. A tendência reflete, adicionalmente, a fragmentação da representação partidária, que passou de 17 para 28 legendas, entre 1999 e 2018 (Gráfico 6). 


\section{GRÁFICO 6 NÚMERO DE LEGENDAS PARTIDÁRIAS COM FILIADOS NOMEADOS PARA CARGOS DE CONFIANÇA, POR GRUPOS DE DAS (1999-2018)18}

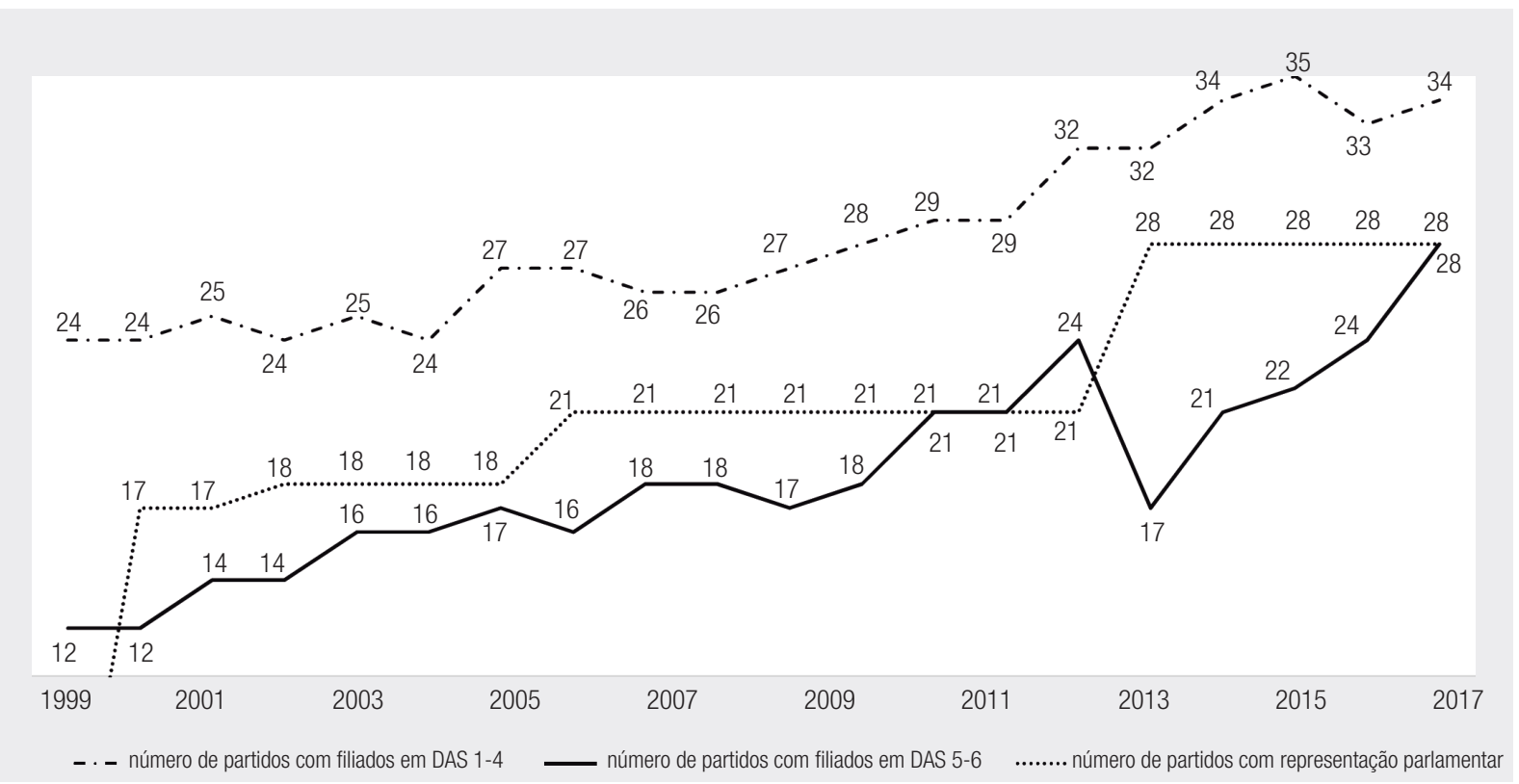

Fonte: Elaborado pelos autores.

Os dados não possibilitam avaliar se há outras formas de politização mais relevantes, alternativas ao recrutamento de filiados, na burocracia política. É razoável esperar que sim, por três motivos. Primeiro, a frágil identidade societária e programática dos partidos enfraquece as exigências de escolhas condicionadas pelo signo da filiação, mas motivadas por afinidades nas preferências. Segundo, entre a burocracia que transita na Esplanada, muitos dos mais aguerridos defensores de programas partidários não figurarem nas listas de filiação das legendas, embora a adesão informal a elas seja patente. Terceiro, as fontes alternativas de politização que se originam em redes políticas não partidárias são importantes, e correm por fora dos partidos, como documentado em Lopez e Praça (2015) ${ }^{19}$.

O reduzido percentual de filiados não significa, por fim, que preferências comuns entre os escolhidos, ou afinidades entre burocratas e políticos, sejam irrelevantes. Ao contrário, a afinidade de preferências é, presumivelmente, relevante e denota o mais genuíno sentido de politizar a burocracia, mas não depende do ato formal de filiação.

\footnotetext{
${ }^{18}$ O número de filiados a partidos nos postos de DAS 1 a 4 e DAS 5-6 supera o número de partidos com representação parlamentar, pois alguns ocupantes de cargos comissionados são filiados a legendas sem representação parlamentar - como é o caso de partidos como o PCB e o PSTU.

${ }^{19}$ Por exemplo, o Ministério da Justiça, em certo momento, apresentava entre seus quadros de alto escalão escolhidos dos círculos profissionais formados no Largo de São Francisco, em São Paulo, não por origem partidária. Loureiro, Abrucio, e Rosa (1998) e Codato, Dantas, Aguiar, e Calabrez (2018) apresentam exemplos adicionais para o setor econômico.
} 


\section{AS TAXAS DE FILIAÇÃO E OS ESTUDOS SOBRE 0 EXECUTIVO}

Os dados aqui apresentados sugerem que, para além da nomeação dos Ministros, é necessário considerar as nomeações no interior da burocracia para dimensionar a real influência dos partidos sobre a agenda do Executivo e para compreender melhor as estratégias de divisão de poder.

Um passo adicional necessário é analisar como as filiações variaram entre áreas de políticas e ministérios. A resposta à divisão inter e intraministerial é importante, ainda, para indicar quão homogênea é a presença partidária nas agências do Estado.

Alguns aspectos adicionais devem ser considerados em análises para compreender o perfil dos selecionados para a burocracia dirigente federal. Primeiro, que as nomeações de integrantes das carreiras é um critério relevante e dominante para a escolha dos cargos, embora a proporção diminua nos níveis superiores. Segundo, que os critérios dos nomeados sem vínculos partidários, mas ideologicamente próximos, são decisivos na escolha dos quadros. Esse ponto consta nos estudos de caso realizados em autarquias, como o Banco Central do Brasil (Olivieri, 2007), e no Ministério da Fazenda (Codato et al., 2018; Loureiro et al., 1998). Em geral, o que a leitura dos casos aponta é que a presença partidária na burocracia dirigente é bastante condicionada pela história institucional dos órgãos federais, a natureza das políticas e por redes extrapartidárias de filiação, tais como vínculos na academia. Essas diferentes gramáticas (Nunes, 1997) definem um cenário mais multifacetado do que a lógica das filiações pode captar.

Os dados também apontam maior representação do PT em seus respectivos mandatos presidenciais. Seria preciso um estudo mais detalhado para verificar se a diferença se deve a uma oferta maior de quadros partidários desse partido - vis-à-vis os demais partidos - ou maior demanda de poder por seus correligionários - amplificada pela diversidade de façõos internas.

É relevante, por fim, considerar a hierarquia de poder efetivo nos cargos. Por esse termo denominamos os recursos de poder intrínseco à natureza da função, não à hierarquia do cargo. Ser chefe de gabinete do ministro tem natureza bem diversa de ser superintendente em uma agência regional. Embora estejam em posições hierárquicas equivalentes, o segundo seria objeto de maior interesse político partidário. Da mesma forma, os responsáveis por celebrar ou aprovar contratos vultosos têm posições que são mais decisivas do que outras funções situadas em níveis hierárquicos intermediários. Passar um "pente fino" na natureza das atividades entre os níveis e diferenciar a natureza das funções vai esclarecer onde a luta política pelo controle partidário é mais forte.

\section{CONSIDERAÇÕES FINAIS}

Neste artigo, apresentamos alguns indicadores e tendências sobre a filiação partidária de nomeados em cargos de DAS da burocracia federal.

O percentual moderado de filiados a partidos nos cargos do médio escalão (12\%) e do alto escalão (abaixo de 30\%), sugere brando controle da identidade político-partidária dos ingressantes na burocracia de livre provimento. Os nomeados para cargos de DAS sem vínculo com o setor público têm maior percentual de filiados.

Nossa análise revela que os presidentes - e seus partidos - adotaram estratégias diferentes para dividir o poder administrativo. Nas gestões do PT houve maior percentual médio de filiados aos cargos da burocracia dirigente e maior concentração de filiados no partido presidencial, em comparação ao segundo mandato FHC e ao governo Temer. Ao lado de potenciais diferenças nas estratégias de 
governo, podem existir diferenças nas características programáticas, organizacionais e estratégias de ação dos principais partidos que governaram o país, desde o final dos anos 1990.

Argumentamos que os dados sobre a nomeação de filiados na burocracia federal de médio e alto escalão são uma relevante fonte de captura de informações sobre a influência partidária as escolhas, mas apenas uma das muitas formas possíveis de conexão - embora a mais explícita - entre nomeados e partidos. Canais alternativos à filiação formal podem ser um instrumento mais relevante de vínculos entre nomeantes e nomeados, tais como redes profissionais e de amizade.

Em si, maiores taxas de filiação ou maior partidarização da alta burocracia não são intrinsecamente indesejáveis. Elas podem ampliar a coordenação intersetorial em agendas comandadas pelo centro de governo, notadamente a Presidência da República. Em quaisquer casos, compreender como o poder da burocracia dirigente é repartido, em um sistema cada vez mais fragmentado, representa um passo para conferir maior inteligibilidade às estratégias de gestão da coalizão em cada governo e para identificar como elas afetam o sucesso do presidente na arena legislativa. 


\section{REFERÊNCIAS}

Almeida, A. (2018). Banco de dados de ministros, coalizões e gabinetes no Brasil 1985-2018. Brasília, DF: Instituto de Pesquisa Econômica Aplicada.

Ames, B. (1995). The deadlock of democracy in Brazil. Ann Arbor, MI: University of Michigan Press.

Amorim, O., Neto. (2000). Gabinetes presidenciais, ciclos eleitorais e disciplina legislativa no Brasil. Dados, 3(43), 479-519.

Amorim, O., Neto. (2019). Cabinets and coalitional presidentialism. In B. Ames (Ed.), Handbook of Brazilian politics (pp. 293-312). New York, NY: Routledge.

Barberia, L., \& Praça, S. (n.d.). Who gets political appointments? Party loyalty and bureaucratic expertise in Brazil. Recuperado de https://cienciapolitica.org. br/system/files/documentos/eventos/2017/03/whogets-political-appointments-party-loyalty-and.pdf

Barbosa, K., \& Ferreira, F. (2019, January). Occupy government: democracy and the dynamics of personnel decisions and public finances (NBER Working Paper No. 25501). Recuperado de https://www.nber.org/ papers/w25501

Bertholini, F., \& Pereira, C. (2017). Pagando o preço de governar: custos de gerência de coalizão no presidencialismo brasileiro. Revista de Administração Pública, 51(4), 528-550.

Calvo, E., Guarnieri, F., \& Limongi, F. (2015). Why coalitions? Party system fragmentation, small party bias, and preferential vote in Brazil. Electoral Studies, $39,219-229$.

Cavalcante, P., \& Lotta, G. (Orgs.). (2015). Burocracia de médio escalão: perfil, trajetória e atuação. Brasília, DF: Escola Nacional de Administração Pública.

Codato, A., Dantas, E., Aguiar, E. M., Júnior, \& Calabrez, F. (2018). Prosopografia dos ajudantes do Ministério da Fazenda: uma análise das lógicas de recrutamento, dos itinerários profissionais e do perfil social do segundo escalão. In Anais do 410 Encontro da Associação Nacional de Pós-Graduação e Pesquisa em Ciências Sociais. Caxambu, MG.

D’Araujo, M. C., \& Lameirão, C. (2010). A elite dirigente do governo Lula. Rio de Janeiro, RJ: Ed. FGV.
D’Araújo, C.; \& Lameirão, C. (2011). Dirigentes públicos federais de alto escalão no governo Lula. In R. Nogueira, \& J. C. Cardoso, Jr. (Eds.), Burocracia e ocupação no setor público brasileiro (pp. 91-131). Brasília, DF: Instituto de Pesquisa Econômica Aplicada.

D’Araujo, M. C., \& Petek, J. (2018). Recrutamento e perfil dos dirigentes públicos brasileiros nas áreas econômicas e sociais entre 1995 e 2012. Revista de Administração Pública, 52(5), 840-862.

Decreto n. 5.497, de 21 de julho de 2005. (2005). Dispõe sobre o provimento de cargos em comissão do Grupo-Direção e Assessoramento Superiores - DAS, níveis 1 a 4, por servidores de carreira, no âmbito da administração pública federal. Brasília, DF.

Decreto n. 9.021, de 31 de março de 2017. (2017). Altera o Decreto n. 5.497, de 21 de julho de 2005, que dispõe sobre o provimento de cargos em comissão do Grupo-Direção e Assessoramento Superiores - DAS, níveis 1 a 4, por servidores de carreira, no âmbito da administração pública federal. Brasília, DF.

Franz, P., \& Codato, A. (2018). Estabilidad y inestabilidad ministerial en el presidencialismo brasileño. In A. Codato, \& F. Espinoza (Ed.), Élites en las Américas: diferentes perspectivas (pp. 319-345). Curitiba, PR: Ed. UFPR.

Gailmard, S., \& Patty, J. (2007). Slackers and zealot: civil service, policy discretion, and bureaucratic expertise. American Journal of Political Science, 51(4), 873-889.

Gerring, J. (2012). Mere description. British Journal of Political Science, 42(4), 721-746.

Grindle, M. (2012). Jobs for the boys: patronage and the State in comparative perspective. Cambridge, MA: Harvard University Press.

Guedes, B. (1994). Politician's dilemma: building State capacity in Latin America. Berkeley, CA: University of California Press.

Hammond, T., \& Knott, J. (1996). Who controls the bureaucracy? Presidential power, congressional dominance, legal constraints, and bureaucratic autonomy in a model of multi-institutional policymaking. The Journal of Law, Economics, and Organization, 12(1), 119-166. 
Kopecký, P., Mair, P., \& Spirova, M. (Eds.). (2012). Party patronage and party government in European democracies. Oxford, England: Oxford University Press.

Kopecký, P., Meyer-Sahling, J. H., Panizza, F., Scherlis, G., Schuster, C., \& Spirova, M. S. (2016). Party patronage in contemporary democracies: results from an expert survey in 22 countries from five regions. European Journal of Political Research, $55,416-431$.

Lameirão, C. (2011a). A ordenação dos cargos de direção e assessoramento superiores (DAS) como estratégia para o fortalecimento institucional e decisório do presidente da República. In J. Cardoso, Jr., \& R. Pires (Orgs.), Gestão pública e desenvolvimento: desafios e perspectivas (pp. 175198). Brasília, DF: Instituto de Pesquisa Econômica Aplicada.

Lameirão, C. (2013). A Casa Civil como estrutura de poder e controle da Presidência: gênese, trajetória e o seu desenvolvimento institucional no governo FHC. (Tese de Doutorado). Universidade Federal Fluminense, Niterói, RJ.

Lameirão, C. (2015). Os níveis de controle da presidência sobre a coordenação governamental e a coalizão partidária (1995-2010). In F. Lopez (Ed.), Cargos de confiança no presidencialismo de coalizão brasileiro (pp. 165-208). Brasília, DF: Instituto de Pesquisa Econômica Aplicada.

Lewis, D. (2008). The politics of presidential appointments: political control and bureaucratic performance. Princeton, NJ: Princeton University Press.

Lopez, F. (2015). Evolução e perfil dos nomeados na administração pública federal (1999-2014) (Nota Técnica n. 16). Brasília, DF: Instituto de Pesquisa Econômica Aplicada.

Lopez, F., Bugarin, M. \& Bugarin, K. (2015). Mudanças político-partidárias e rotatividade dos cargos de confiança. In F. Lopez (Org.), Cargos de confiança no presidencialismo de coalizão (pp. 33-70). Brasília, DF: Instituto de Pesquisa Econômica Aplicada.

Lopez, F., \& Praça, S. (2015). Critérios e lógicas de nomeação para o alto escalão da burocracia federal brasileira. In F. Lopez (Ed.), Cargos de confiança no presidencialismo de coalizão brasileiro (pp. 107138). Brasília, DF: Instituto de Pesquisa Econômica Aplicada.
Lopez, F., \& Praça, S. (2018). Cargos de confiança e políticas públicas no Executivo federal. In R. Pires, G. Lotta, \& V. E. Oliveira (Orgs.), Burocracia e políticas públicas no Brasil: interseções analíticas (pp. 141-160). Brasília, DF: Instituto de Pesquisa Econômica Aplicada.

Lopez, F., \& Silva, T. (2019). O carrossel burocrático nos cargos de confiança da burocracia federal: análise de sobrevivência dos nomeados para cargos de direção e assessoramento superio (1999-2016) (Manuscrito não publicado).

Loureiro, M., Abrucio, F., \& Rosa, C. (1998). Radiografia da alta burocracia brasileira: o caso do Ministério da Fazenda. Revista do Serviço Público, 49(4), 46-82.

Mainwaring, S. (1991). Politicians, parties, and electoral systems: Brazil in comparative perspective. Comparative Politics, 24(1), 21-43.

Mauerberg, A. (2016). Cabinet composition and assessment of a multiparty presidential system (Ph.D. Thesis). São Paulo, SP: Fundação Getulio Vargas.

Mikkelsen, K. (2018). Old habits die hard, sometimes: history and civil service politicization in Europe. International Review of Administrative Sciences, 84(4), 803-819.

Nexo. (2018, 13 de julho). A genealogia e o perfil dos partidos brasileiros. Recuperado de https:// www.nexojornal.com.br/especial/2018/07/16/Agenealogia-e-o-perfil-dos-partidos-brasileiros

Nogueira, R., \& Cardoso, J., Jr. (Eds.). (2011). Burocracia e ocupação no setor público brasileiro. Brasília, DF: Instituto de Pesquisa Econômica Aplicada.

Nunes, E. (1997). A gramática política do Brasil: clientelismo e insulamento burocrático. Brasília, DF: Escola Nacional de Administração Pública.

Olivieri, C. (2007). Política, burocracia e redes sociais: as nomeações para o alto escalão do Banco Central do Brasil. Revista de Sociologia e Política, 29, 147-168.

Pacheco, R. (2010). O debate sobre dirigentes públicos: atores, argumentos e ambiguidades. In F. Abrucio, M. Loureiro, \& R. Pacheco (Orgs.), Burocracia e política no Brasil: desafios para o Estado democrático no século XXI (pp. 277-306). São Paulo, SP: Ed. FGV. 
Page, E., \& Wright, V. (Eds.). (1999). Bureaucratic elites in Western European States: a comparative analysis of top officials. Oxford, England: Oxford University Press.

Painter, M., \& Peters, G. (Eds.). 2011. Tradition and public administration. London, England: PalgraveMacMillan.

Pereira, C., Batista, M., Praça, S., \& Lopez, F.. (2017). Watchdogs in our midst: how presidents monitor coalitions in Brazil's multiparty presidential regime. Latin America Politics and Society, 59(3), 27-47.F

Pereira, C., \& Bertholini, F. (2019). Coalition management in multiparty presidential regimes. In B. Ames (Ed.), Handbook of Brazilian Politics (pp. 313-330). New York, NY: Routledge.

Peters, G. (1999). La politica de la burocracia. Mexico, DF: Fondo de Cultura Económica.

Peters, G., \& Pierre, J. (Eds.). (2004). Politicization of the civil service in comparative perspective: the quest for control. New York, NY: Routledge.
Praça, S., Freitas, A., \& Hoepers, B. (2011). Political appointments and coalition management in Brazil, 2007-2010. Journal of Politics in Latin America, 3(2), 141-172.

Praça, S., \& Lopez, F. (2019). Political appointments, political parties and bureaucracy. In B. Ames (Ed.), Handbook of Brazilian politics (pp. 358-370). New York, NY: Routledge.

Raile, E., Pereira, C., \& Power, T. (2011). The executive toolbox: building legislative support in multiparty presidential regime. Political Research Quarterly, 64(2), 323-334.

Tribunal Superior Eleitoral. (n.d.). Relação de filiados. Recuperado de http://www.tse.jus.br/ partidos/filiacao-partidaria/relacao-de-filiados

Weber, M. (2002). Economia e sociedade. Brasília, DF: Ed. UnB.

Yesilkagit, K., \& Van Thiel, S. (2008). Political influence and bureaucratic autonomy. Public Organization Review, 14, 137-153.

\section{Felix G. Lopez}

https://orcid.org/0000-0003-4725-4473

Doutor em Sociologia e pesquisador da Diretoria de Estudos sobre Estado, Instituições e Democracia, no Instituto de Pesquisa Econômica Aplicada (Diest/Ipea). E-mail: felixglopez@gmail.com

\section{Thiago Moreira da Silva}

https://orcid.org/0000-0001-8451-8621

Doutor em Ciência Política e pesquisador de Pós-Doutorado no Instituto de Estudos Sociais e Políticos da Universidade do Estado do Rio de Janeiro (IESP-UERJ).E-mail: thiagomoreira@iesp.uerj.br 